\title{
Double checking the administration of medicines: what is the evidence? A systematic review
}

\author{
Zayed Alsulami, Sharon Conroy, Imti Choonara
}

Academic Division of Child Health, University of Nottingham, Derbyshire Children's Hospital, Derby, UK

\section{Correspondence to}

Zayed Alsulami, Academic Division of Child Health, University of Nottingham, Derbyshire Children's Hospital, The Medical School, Clinical Sciences Wing, Uttoxeter Road, Derby DE22 3DT, UK: mzxza@nottingham.ac.uk

Accepted 14 March 2012

\section{ABSTRACT}

Objective To evaluate the evidence for double checking the administration of medicines.

Design A systematic search of six electronic databases-Embase, Medline, British Nursing Index and Archive, CINAHL, National electronic library for Medicines (NeLM) and PsycINFO—for all articles describing double checking of medication and dose calculation, for either dispensing or administration in both adults and children up to and including October 2010.

Results Sixteen articles met the inclusion criteria. There were only three quantitative studies. Only one of these was a randomised controlled clinical trial in a clinical setting. This study showed a statistically significant reduction in the medication error rate from $2.98(95 \% \mathrm{Cl} 2.45$ to 3.51$)$ to $2.12(95 \% \mathrm{Cl} 1.69$ to 2.55) per 1000 medications administered with double checking. One study reported a reduction in dispensing errors, by a hospital pharmacy, from 9.8 to 6 per year following the introduction of double checking. The majority of the studies were qualitative and involved interviews, focus groups and questionnaires

Conclusion There is insufficient evidence to either support or refute the practice of double checking the administration of medicines. Clinical trials are needed to establish whether double checking medicines are effective in reducing medication errors.

\section{INTRODUCTION}

Patient and medication safety is a priority for healthcare providers. ${ }^{1}$ Human mistakes are a source of medication errors and can occur in each stage of the medication treatment process; prescribing, dispensing, administration and documentation. ${ }^{2}$ Medication errors are a significant problem in children. Over an 8-year period in the UK, there were at least 29 deaths associated with medication errors. ${ }^{3}$ The greatest number of medication errors is thought to occur during the process of administration of medicines. ${ }^{4}$ Reduction of medication errors leads to an improvement in patient safety. ${ }^{5}$ Double checking is one of the strategies that has been used in both medical and non-medical areas. ${ }^{6}$ In aviation, double checking or checklists have become a mandatory part of practice, to reduce human error and when introduced, it significantly decreases the risk of errors and improves the outcomes in aviation safety. ${ }^{6}$

In healthcare systems, blood transfusion and radiotherapy have already followed and implemented the checklist or double checking concept to improve patient safety. ${ }^{8}$ Double checking of medications has been recommended as an intervention to reduce medication errors and a

\section{What is already known about this topic}

- Medication errors are a significant problem in paediatric patients.

- Administration errors are the most common type of medication error.

- Double checking of administration of medicines is thought to reduce the risk of medication errors.

\section{What this study adds}

- There is insufficient scientific evidence to justify double checking of medicines.

- Clinical trials are needed to evaluate whether double checking of the administration of medicines reduces medication errors.

recommended additional step to protect vulnerable patients, such as children. ${ }^{9-11}$ Double checking is now a standard practice in many children's hospitals and paediatric units in the UK.

Double checking is defined as a procedure that requires two qualified health professionals, usually nurses, independently checking the medication before administration to the patients. ${ }^{12}$ The word 'independent' means a second person follows a series of steps to confirm that they agree with the first person for example, to arrive at a calculation without prior knowledge of any previous calculation. ${ }^{12}$ This approach is thought to reduce the possibility of bias which occurs when the person checking the medication is likely to see what they expect to see even if an error has occurred. This process is also used in many pharmacy departments where the check is often separated in time and space by items for checking being placed in a separate area to where they are dispensed.

This systematic review was performed to determine the existing evidence base on the effectiveness of the double checking process by two health professionals in reducing medication error rates in dose calculation, dispensing and administration.

\section{METHODS}

A search for articles, describing double checking during drug dose calculation, dispensing and administration in both children and adults, was conducted in October 2010. Also included were any studies 
reporting a double checking process for devices that were used in the patient medication administration process. In this search, six electronic databases were used: EMBASE (1980 to October 2010), MEDLINE (1950 to October 2010), BRITISH NURSING INDEX \& ARCHIVE (1985 to October 2010), CUMULATIVE INDEX to NURSING \& ALLIED HEALTH LITERATURE (CINAHL) (1982 to October 2010), National electronic library for Medicines (NeLM) (1998 to October 2010) and PsycINFO (1806 to October 2010). The search strategy included adults and children because evidence identified from studies in adults may be applicable to children. The search strategy included all languages and types of trials and studies.

In this search, the keyword 'double check' was used in combination with AND of the terms 'drug safety' OR 'nurse' OR 'pharmacist' OR 'pharmacy technician' OR 'drug administration', OR 'medication administration', in order to include all articles that had been published in the databases listed above. The term 'double check' was used as it is the term used by healthcare professionals and in most hospital policies. Duplicates were identified and removed.

All abstracts and/or titles were evaluated and assessed according to the inclusion criteria described below. Inclusion criteria were papers assessing or discussing double checking of medication before drug dose calculation, dispensing or administration in hospitalised patients. We included quantitative and qualitative studies to obtain a full picture of the double checking process in drug administration.

Full articles of the relevant abstracts were retrieved. The reference lists of the retrieved articles were searched manually in order to identify additional appropriate studies. The relevant additional articles that met the inclusion criteria were also obtained. Any studies or articles, that were obviously not related to double checking and also opinion papers, letters, case reports and comments, were excluded.

All identified abstracts were read for their relevance to the inclusion and exclusion criteria. Full articles that were considered relevant were obtained and examined, and the following data was extracted: year of study; study design and sample size; patient population and place of study; efficacy outcome measures; type of medication in each study; error rate with double checking and without if applicable.

We also searched Pharmline through the NeLM database and no further studies were identified.

\section{RESULTS}

The search strategies yielded 752 abstracts from the six databases. There were 289 duplicates. A further 357 articles were excluded because they were unrelated to doublechecking of the medication treatment process (figure 1). The full text of the articles that were remaining (106 references) was reviewed, and 92 references were also excluded because they were unrelated to double checking of medications. Two additional studies were added after the references of relevant articles were reviewed manually. In total, 16 studies identified double checking of the medication treatment process and are included in this systematic review. All studies identified were in English. No studies in other languages were identified.

There were three quantitative studies. ${ }^{13-15}$ Two studies used both qualitative and quantitative methods. ${ }^{16} 17$

Nine were qualitative studies (questionnaire and interviews). ${ }^{18-26}$ Two studies were systematic reviews that focused on reducing medication errors in older adults ${ }^{27}$ and intravenous drug administration in anaesthesia. ${ }^{28}$

\section{Quantitative studies}

Three quantitative studies were conducted to assess the effectiveness of double checking processes in reducing medication errors for hospitalised patients (table 1). The first study was conducted in Australia in 1992.13 It was a cross over study in three wards in a geriatric hospital (table 1). A total of 319 medication errors were detected during the 46 week study period. The authors found that the use of two nurses, as opposed to one, in administering medication significantly reduced the medication error rate to 2.12 per 1000 medications administered (95\% CI 1.69 to 2.55$)$. The error rate with a single nurse was 2.98 per 1000 medications administered (95\% CI 2.45 to 3.51). The clinical advantages were unclear.

The second study was a retrospective review of all medication error reports in a large children's hospital in the UK completed prospectively from April 1994 to August 1999 (65 months) ${ }^{14}$ (table 1). The main finding was that 195 medication errors were reported during the study period. One hundred and thirty of these errors occurred despite double checking. There were 58 errors, where it was confirmed that double checking did not occur, and in seven errors it was uncertain whether double checking was performed or not. In addition, during this study period a new pharmacy policy was introduced, where two people were involved in double checking all drugs before dispensing. This resulted in a reduction in drug dispensing errors. Eighteen dispensing errors were reported in 22 months, that is 9.8 errors per year, before the double checking process was introduced. Following the introduction of double checking, there were only 21 dispensing errors in 43 months, that is six errors per year.

The third study was a simulation study of outpatient chemotherapy administration involving 10 nurses from the unit in a Canadian hospital ${ }^{15}$ (table 1). Two separate checklists for an ambulatory infusion pump were used to determine the effectiveness in detecting medication administration errors during nurses' practice. This study focused specifically on the administration of intravenous medicines, whereas the other studies included oral and intravenous medicines. In this study, a total of 130 errors were detected. Overall, the new checklist helped nurses to detect $59 \%$ errors compared with $51 \%$ errors with the old checklists. There was no significant difference in the detection of pump programming errors between the two checklists. There was a major difference in error detection between the two checklists in relation to patient identification $(16 / 20,80 \%$ vs $3 / 20,15 \%)$ respectively.

\section{Quantitative and qualitative studies}

Two studies included quantitative and qualitative data. The first study monitored medication errors after double checking for 7 months and then monitored medication errors after single checking for a similar period of time in an Australian adult hospital. ${ }^{16}$ This was an observational study evaluating the effect of a change in policy that was introduced in the hospital whereby single checking replaced double checking. Unfortunately, the number of medication errors reported in each time period was very small. There were five reports during the period with double checking compared with four reports during the period with single checking. The very small number of reports suggests that not all medication errors were reported and makes statistical comparison impossible. The qualitative part of the study consisted of 129 nurses completing a questionnaire which asked them if they preferred double checking or single checking. The questionnaires revealed that the nurses preferred single checking. 


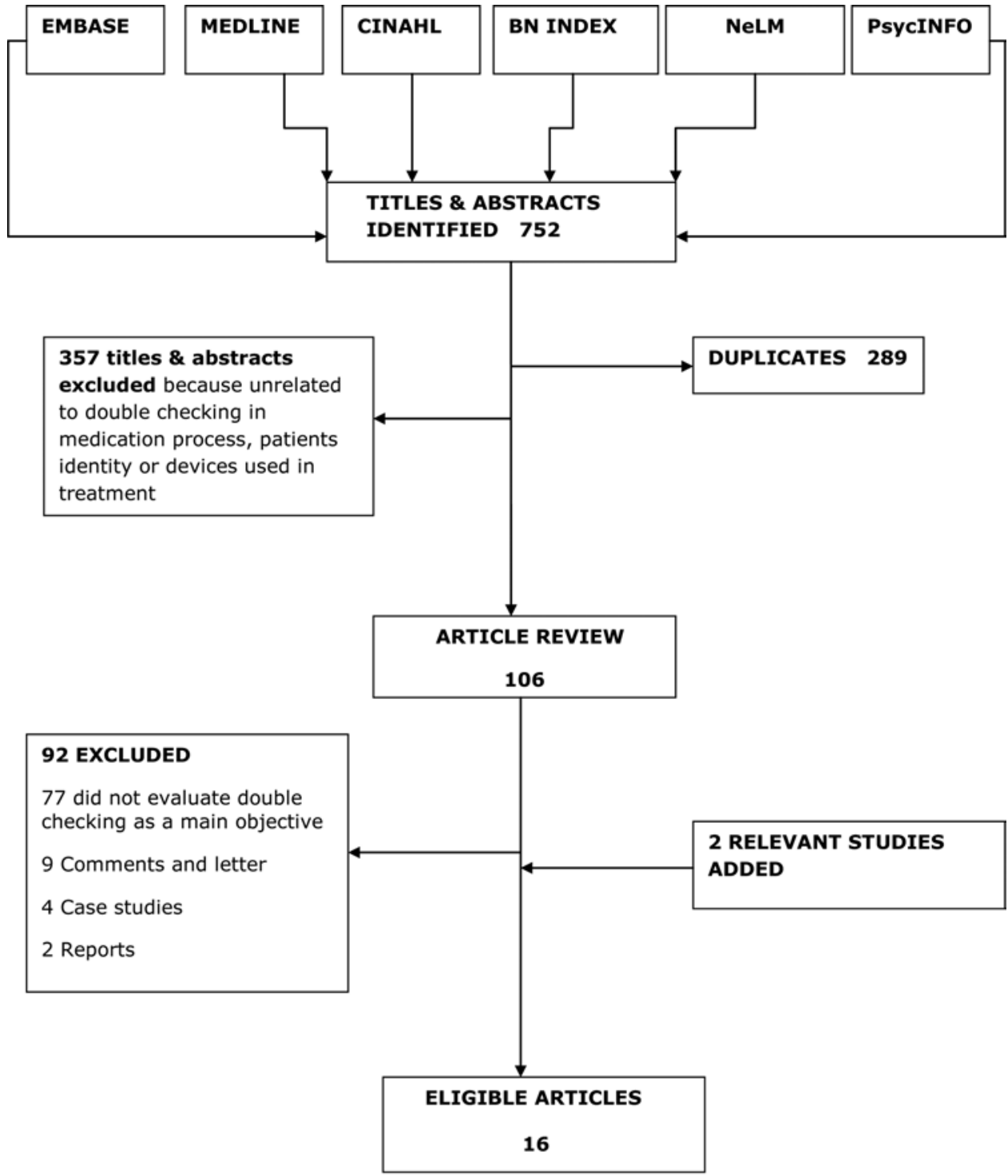

Figure 1 Flow diagram of search and review process.

The other study involved a review of 52 medication errors that occurred in a general hospital in Hong Kong. ${ }^{17}$ However, the review of the medication errors did not contain any information about double checking. The qualitative part of the study involved focus groups and a questionnaire in which 466 out of 748 nurses returned. The nurses felt that double checking was preferable to triple checking. There was strong support for the principles of the five rights for drug administration (right patient, right drug, right dose, right route and right time).

\section{Qualitative studies}

There were nine qualitative studies. ${ }^{18-26}$ These studies used interviews, questionnaires or focus groups and consisted of asking the health professionals involved whether they felt double checking was beneficial or not (table 2). In six of the studies, health professionals preferred double checking as they felt this was more likely to detect drug administration errors. ${ }^{18-212526}$ In two of the studies, the majority of the participants felt that single checking was adequate. ${ }^{22} 23$ One study identified the double checking process as an intervention with significant potential to reduce medication errors but did not ask the participant to compare single and double checking. ${ }^{24}$

\section{Previous systematic reviews}

Two previous systematic reviews were identified in this review. One evaluated interventions in minimising or reducing medication errors in older adults. ${ }^{27}$ They identified a total of 20 studies and three systematic reviews, but only two studies evaluated the effectiveness of single checking against double checking. ${ }^{14} 16$ The second systematic review identified was conducted to develop evidence based recommendations to minimise errors in intravenous drug administration in anaesthesia. ${ }^{28}$

\section{DISCUSSION}

Medication errors are a significant problem. Each year several children will die in the UK as a result of medication errors. ${ }^{3}$ A previous study in the UK has suggested almost one in five 
Table 1 Quantitative studies of actual error rates

\begin{tabular}{|c|c|c|c|c|c|c|c|}
\hline Type of study & Intervention & Settings & $\begin{array}{l}\text { Study } \\
\text { population }\end{array}$ & Drugs & Main findings & Outcome & References \\
\hline $\begin{array}{l}\text { Cross over } \\
\text { study }\end{array}$ & $\begin{array}{l}\text { Three wards included } \\
\text { WARD A: control (with } \\
\text { two nurses) for first } \\
23 \text { weeks, and trial for } \\
\text { second } 23 \text { weeks (with } \\
\text { one nurse) } \\
\text { WARD B: trial with one } \\
\text { nurse for first } 23 \text { week, } \\
\text { and control (with two } \\
\text { nurses) for second } 23 \\
\text { weeks } \\
\text { WARD C: control for all } \\
\text { study period with two } \\
\text { nurses administering }\end{array}$ & $\begin{array}{l}\text { Three wards } \\
\text { of a geriatric } \\
\text { assessment } \\
\text { and } \\
\text { rehabilitation } \\
\text { unit, Australia }\end{array}$ & $\begin{array}{l}\text { Registered } \\
\text { nurses }\end{array}$ & $\begin{array}{l}\text { Non- } \\
\text { restricted } \\
\text { medications }\end{array}$ & $\begin{array}{l}\text { Total errors }=319 \text {; error } \\
\text { rate/ } 1000 \text { medicines } \\
\text { administered; one nurse } \\
2.98 ; 95 \% \mathrm{Cl} 2.45 \text { to } 3.51 \text {; } \\
\text { two nurses } 2.12 ; 95 \% \mathrm{Cl} \\
1.69 \text { to } 2.55\end{array}$ & $\begin{array}{l}\text { The use of two nurses to } \\
\text { administer medication, } \\
\text { statistically significantly } \\
\text { reduced the medication } \\
\text { error rate, but the } \\
\text { clinical advantages were } \\
\text { uncertain }\end{array}$ & 13 \\
\hline $\begin{array}{l}\text { Retrospective } \\
\text { study }\end{array}$ & $\begin{array}{l}\text { Retrospective review of } \\
\text { medication error reports } \\
\text { completed from April } \\
1994 \text { to August } 1999 \\
\text { (65 months) }\end{array}$ & $\begin{array}{l}\text { This study } \\
\text { reviewed } \\
\text { data routinely } \\
\text { collected } \\
\text { in Royal } \\
\text { Hospital for } \\
\text { Sick Children, } \\
\text { Glasgow, UK }\end{array}$ & $\begin{array}{l}\text { Nurses and } \\
\text { pharmacy staff }\end{array}$ & All medicines & $\begin{array}{l}\text { Total errors }=195 ; \\
\text { dispensing errors }=39 ; \\
\text { Without double checking; } \\
18 \text { dispensing errors } \\
\text { reported in } 22 \text { month } \\
\text { period, that is, } 9.8 \text { per year; } \\
\text { With double checking; } 21 \\
\text { dispensing errors reported } \\
\text { in } 43 \text { months period, that is, } \\
6 \text { per year }\end{array}$ & $\begin{array}{l}\text { The introduction of a } \\
\text { policy of double checking } \\
\text { for all drugs dispensed } \\
\text { by pharmacy staff led to } \\
\text { a reduction in dispensing } \\
\text { errors from } 9.8 \text { to } 6 \text { per year }\end{array}$ & 14 \\
\hline $\begin{array}{l}\text { Simulation } \\
\text { study }\end{array}$ & $\begin{array}{l}\text { Two checklists for an } \\
\text { ambulatory infusion } \\
\text { pump were compared, } \\
\text { one old, and one new. } \\
\text { The new checklist had } \\
\text { a specific item to check } \\
\text { patient identity. Study } \\
\text { was focused on the } \\
\text { ability of the second } \\
\text { nurse to detect errors } \\
\text { by using the checklists. } \\
14 \text { pumps were checked } \\
\text { by each nurse }\end{array}$ & $\begin{array}{l}\text { Simulated } \\
\text { setting Toronto } \\
\text { University } \\
\text { Hospital, } \\
\text { Canada }\end{array}$ & $\begin{array}{l}10 \text { Registered } \\
\text { nurses }\end{array}$ & Chemotherapy & $\begin{array}{l}\text { Overall, the new checklist } \\
\text { helped nurses to detect } \\
76 / 130(59 \%) \text { of errors } \\
\text { compared with } 66 / 130 \\
(51 \%) \text { with old checklist; } \\
(p<0.01)\end{array}$ & $\begin{array}{l}\text { No significant difference } \\
\text { in detection of pump } \\
\text { programming errors, but } \\
\text { detection of errors in } \\
\text { patient identification with } \\
\text { new checklist }(80 \%) \text { was } \\
\text { significantly higher than } \\
\text { with the old checklist (15\%) }\end{array}$ & 15 \\
\hline
\end{tabular}

administrations of medicines may be associated with an error. ${ }^{4}$ Medication errors are therefore a major clinical problem and measures to reduce medication errors should be welcomed.

Double checking was introduced into nursing practice, as it was assumed that double checking would reduce medication errors. It is now standard nursing policy in many children's hospitals. ${ }^{29}$ Double checking the administration of medicines is labour intensive in that it requires two qualified health professionals. This has a significant impact on nursing time and it is therefore surprising that double checking is a widespread process with minimal supportive evidence. It is of concern that there has only been one randomised controlled clinical trial, a study involving adult patients on a geriatric unit in Australia. ${ }^{13}$ This clinical trial suggested that double checking may be beneficial. The retrospective review of medication errors in Glasgow Children's Hospital reported that dispensing errors reduced following the introduction of double checking procedures in the pharmacy department. ${ }^{14}$ However, the overall incidence of reported errors in this study was very small and this suggests that a significant number of errors were not reported. This questions the validity of the findings in this paper.

The vast majority of the papers identified in the systematic review consisted of asking health professionals (usually nurses) whether they felt double checking was helpful or not. The majority of the studies confirmed that the nursing staff felt that double checking, if done properly, would result in fewer medication errors. However, these studies all identified that there were practical problems associated with ensuring the double checking process was performed correctly. These often involved staff shortages or an emergency situation. Three studies suggested that nurses preferred single checking. ${ }^{16} 2223$ Reported disadvantages of double checking were that the process is time consuming, reduces the responsibility and may be associated with deference to authority. ${ }^{18}$ It is dependent on the availability of sufficient nurses. Some nurses raised concerns that the double checking process reduced their responsibility and may actually predispose to medication errors. It was felt by some nurses that double checking should be used only in high risk patients (neonates, infants or with high risk medications such as chemotherapy, opiates and intravenous routes)..$^{25}$

A number of different interventions have been suggested to reduce errors in calculations of paediatric drug doses such as Centralised Intravenous Additives Services, Computerised Physician Order Entry, Unit Dose Dispensing Systems and Intelligent Infusion pumps. ${ }^{24}$ These are likely to contribute to a reduction in other types of paediatric errors though they may also introduce new errors. However, it is beyond the scope of this article to discuss them further.

The time saving from the single checking process was estimated in two studies. ${ }^{1416}$ In the randomised controlled clinical trial, the authors found that one nurse rather than two nurses, administering medications would save $17.1 \mathrm{~h}$ of nursing time 
Table 2 Qualitative studies

\begin{tabular}{lllll}
\hline Method & Country & $\begin{array}{l}\text { Number of health } \\
\text { professionals }\end{array}$ & Year & Reference \\
\hline $\begin{array}{l}\text { Focus group } \\
\text { interviews and } \\
\text { questionnaires* }\end{array}$ & Hong Kong & 510 & 2007 & 17 \\
Questionnaires* & Australia & 129 & & \\
Interviews & UK & 40 & 2002 & 16 \\
Interviews & Australia & 12 & 2008 & 18 \\
Focus groups & UK & 25 & 2005 & 19 \\
Focus group & New Zealand & 19 & 2010 & 20 \\
interviews & & 2009 & 21 \\
Questionnaires & Taiwan & 85 & & \\
Questionnaires & Australia & 185 & 2008 & 25 \\
Questionnaires & UK & 35 & 2010 & 26 \\
Questionnaires & UK & 328 & 2007 & 24 \\
Questionnaires & Australia & 124 & 1991 & 22 \\
\hline
\end{tabular}

${ }^{*}$ Additional limited quantitative data.

per 1000 medications administered. ${ }^{13}$ In one study following the introduction of single checking, nursing staff felt that approximately 20 min was saved on each medication round. ${ }^{16}$

We feel that the process of double checking the administration of medicines should be evaluated scientifically. We recognise that there are major practical difficulties in performing such a clinical trial in children within the UK, as double checking is now accepted as a standard nursing procedure. However, one could perform clinical trials in adult inpatients, where double checking is not routinely used, to establish whether double checking is effective in reducing medication errors.

Acknowledgements $Z A$ is a postgraduate research student and sponsored by the Saudi Arabia Government.

Contributors ZA performed the literature search.

Competing interests None.

Provenance and peer review Not commissioned; externally peer reviewed.

\section{REFERENCES}

1. Department of Health. Building a Safer NHS for Patients: Improving Medication safety, 2004

2. Kaushal R, Bates DW, Landrigan C, et al. Medication errors and adverse drug events in pediatric inpatients. JAMA 2001;285:2114-20.

3. Cousins D, Clarkson A, Conroy $\mathrm{S}$, et al. Medication errors in children - an eight year review using press reports. Paed Perinat Drug Ther 2002;5:52-8.

4. Ghaleb MA, Barber N, Franklin BD, et al. The incidence and nature of prescribing and medication administration errors in paediatric inpatients. Arch Dis Child 2010:95:113-18.

5. Lehmann CU, Kim GR. Prevention of medication errors. Clin Perinatol 2005:32:107-23, vii.
6. Hales BM, Pronovost PJ. The checklist-a tool for error management and performance improvement. J Crit Care 2006;21:231-5.

7. Toft B, Mascie-Taylor H. Involuntary automaticity: a work-system induced risk to safe health care. Health Serv Manage Res 2005;18:211-16.

8. Duggan L, Kron T, Howlett S, et al. An independent check of treatment plan, prescription and dose calculation as a QA procedure. Radiother Oncol 1997:42:297-301.

9. American Academy of Pediatrics. Committee on Drugs and Committee on Hospital Care. Pediatrics 2007;102:428-30.

10. Morris F. Adverse medical events in the NICU: epidemiology and prevention NeoReviews 2008;9:e8-e23.

11. Smetzer J. ISMP survey pinpoints weaknesses in medication practices. American Hospital Association, Health Research \& Educational Trust and the Institute for Safe Medication Practices. http://www.medpathways.info (accessed 8 0ctober 2010).

12. ISMP Canada. Lowering the risk of medication errors: independent safety checks. ISMP Canada Safety Bulletin, 2005;5.

13. Kruse H, Johnson A, O'Connell D, et al. Administering non-restricted medications in hospital: the implications and cost of using two nurses. Aust Clin Rev 1992;12: 77-83.

14. Ross LM, Wallace J, Paton JY. Medication errors in a paediatric teaching hospital in the UK: five years operational experience. Arch Dis Child 2000;83:492-7.

15. White RE, Trbovich PL, Easty AC, et al. Checking it twice: an evaluation of checklists for detecting medication errors at the bedside using a chemotherapy model. Qual Saf Health Care 2010;19:562-7.

16. Jarman H, Jacobs E, Zielinski V. Medication study supports registered nurses' competence for single checking. Int J Nurs Pract 2002;8:330-5.

17. Leung SF, Chong SYC, Arthur DG. Reducing medication errors: development of a new model of drug administration for enhancing safe nursing practice. Asian J Nursing 2007:10:191-9.

18. Armitage G. Double checking medicines: defence against error or contributory factor? J Eval Clin Pract 2008;14:513-19.

19. Manias E, Aitken R, Dunning T. How graduate nurses use protocols to manage patients' medications. J Clin Nurs 2005;14:935-44.

20. Evley R, Russell J, Mathew D, et al. Confirming the drugs administered during anaesthesia: a feasibility study in the pilot National Health Service sites, UK. Br J Anaesth 2010;105:289-96.

21. Dickinson A, McCall E, Twomey B, et al. Paediatric nurses' understanding of the process and procedure of double-checking medications. J Clin Nurs 2010;19: 728-35.

22. Winson G. A survey of nurses' attitudes towards single administration of medicines. Nursing Practice 1991;4:20-3.

23. O'Connell B, Crawford S, Tull A, et al. Nurses' attitudes to single checking medications: before and after its use. Int J Nurs Pract 2007;13:377-82.

24. Wong I, Conroy S, Collier JEA, et al. Co-operative of safety of medicines in children (COSMIC): scoping study to identify and analyse interventions used to reduce errors in calculation of paediatric drug doses. Report to the Patient Safety Research Programme (Policy Research Programme of the Department of Health), 2007. http:// www.haps.bham.ac.uk/publichealth/psrp/documents/PSO26_COSMIC_Final_Rep ort. pdf (accessed 22 July 2011).

25. Sheu SJ, Wei IL, Chen $\mathrm{CH}$, et al. Using snowball sampling method with nurses to understand medication administration errors. J Clin Nurs 2009;18:559-69.

26. Davis L, Ware RS, McCann D, et al. Factors influencing paediatric nurses' responses to medication administration. Qual Saf Health Care 2010;19:e4.

27. Hodgkinson B, Koch $\mathrm{S}$, Nay R, et al. Strategies to reduce medication errors with reference to older adults. Int J Evid Based Healthc 2006;4:2-41.

28. Jensen LS, Merry AF, Webster CS, et al. Evidence-based strategies for preventing drug administration errors during anaesthesia. Anaesthesia 2004; 59:493-504.

29. Conroy S, Daver Z, Jones $S$. Use of checking systems in medicines administration with children and young people. Nursing Children and Young People 2012;24:20-4. 


\section{ADC Double checking the administration of medicines: what is the evidence? A systematic review}

Zayed Alsulami, Sharon Conroy and Imti Choonara

Arch Dis Child published online May 1, 2012

doi: 10.1136/archdischild-2011-301093

Updated information and services can be found at:

http://adc.bmj.com/content/early/2012/04/30/archdischild-2011-301093.full.html

These include:

References This article cites 25 articles, 7 of which can be accessed free at: http://adc.bmj.com/content/early/2012/04/30/archdischild-2011-301093.full.html\#ref-list-1

Article cited in:

http://adc.bmj.com/content/early/2012/04/30/archdischild-2011-301093.full.html\#related-urls

$\mathbf{P}<\mathbf{P} \quad$ Published online May 1, 2012 in advance of the print journal.

Email alerting service

Receive free email alerts when new articles cite this article. Sign up in the box at the top right corner of the online article.

Collections

Articles on similar topics can be found in the following collections

Unwanted effects / adverse reactions (70 articles)

Advance online articles have been peer reviewed, accepted for publication, edited and typeset, but have not not yet appeared in the paper journal. Advance online articles are citable and establish publication priority; they are indexed by PubMed from initial publication. Citations to Advance online articles must include the digital object identifier (DOIs) and date of initial publication.

To request permissions go to:

http://group.bmj.com/group/rights-licensing/permissions

To order reprints go to:

http://journals.bmj.com/cgi/reprintform

To subscribe to BMJ go to:

http://group.bmj.com/subscribe/ 


\section{Notes}

Advance online articles have been peer reviewed, accepted for publication, edited and typeset, but have not not yet appeared in the paper journal. Advance online articles are citable and establish publication priority; they are indexed by PubMed from initial publication. Citations to Advance online articles must include the digital object identifier (DOIs) and date of initial publication.

To request permissions go to:

http://group.bmj.com/group/rights-licensing/permissions

To order reprints go to:

http://journals.bmj.com/cgi/reprintform

To subscribe to BMJ go to:

http://group.bmj.com/subscribe/ 